\title{
Phase I/II study of combination therapy with S-1 and CPT-11 for metastatic colorectal cancer
}

\author{
YUJI NAKAFUSA ${ }^{1}$, MASAYUKI TANAKA ${ }^{1}$, TAKAO OHTSUKA ${ }^{1}$, \\ ATSUSHI MIYOSHI ${ }^{1}$, NAOHIKO KOHYA ${ }^{1}$, YOSHIHIKO KITAJIMA ${ }^{1}$, SEIJI SATO ${ }^{1}$, \\ SAKIKO MOCHINAGA $^{2}$, SAWAKO DOHI ${ }^{3}$ and KOHJI MIYAZAKI ${ }^{1}$ \\ ${ }^{1}$ Department of Surgery, Saga University Faculty of Medicine; Divisions of ${ }^{2}$ Pharmacy, and \\ ${ }^{3}$ Nursing, Saga University Hospital, 5-1-1 Nabeshima, Saga 849-8501, Japan
}

Received June 30, 2008; Accepted September 22, 2008

DOI: 10.3892/mmr_00000051

\begin{abstract}
We conducted a Phase I/II study of combination therapy using CPT-11 and S-1 as a first-line treatment for metastatic colorectal cancer. The 28-day treatment cycle consisted of S-1 administered orally from day 1 to 21 and CPT-11 administered intravenously on days 1 and 15 . In the Phase I portion, the dose of S-1 was fixed at $80 \mathrm{mg} / \mathrm{m}^{2} / \mathrm{day}$, while CPT-11 was administered at a starting dose of $60 \mathrm{mg} / \mathrm{m}^{2}$ then stepped up in $20 \mathrm{mg} / \mathrm{m}^{2}$ increments. The maximumtolerated dose was achieved at $80 \mathrm{mg} / \mathrm{m}^{2}$ of CPT- 11 , and the recommended dose was determined to be $60 \mathrm{mg} / \mathrm{m}^{2}$ of CPT- 11 . In the Phase II portion, this therapy exhibited a response rate of $58 \%$, a median progression-free survival of 8.4 months, and a median overall survival of 18.7 months. Toxicity was generally mild and manageable. No patient showed grade 4 toxicity, and grade 3 toxicity was observed in only $18 \%$ of patients. The most frequently observed grade 3 toxicity was diarrhea, at a rate of $6 \%$. The mean relative dose intensity of CPT-11 and S-1 was as high as 98 and 97\%, respectively. In conclusion, combination therapy with CPT-11 and S-1 according to our treatment schedule is effective, safe and highly feasible for metastatic colorectal cancer patients. These data suggest that assessing this combination therapy in a Phase III study would be worthwhile.
\end{abstract}

\section{Introduction}

Colorectal cancer is one of the most common types of cancer, and nearly half of its patients develop metastatic disease (1). Due to recent progress in active agents, chemotherapy has been demonstrated to dramatically improve the survival of patients with metastatic colorectal cancer (2).

Correspondence to: Dr Yuji Nakafusa, Department of Surgery, Saga University Faculty of Medicine, 5-1-1 Nabeshima, Saga 849-8501, Japan

E-mail: nakafusy@cc.saga-u.ac.jp

Key words: S-1, CPT-11, irinotecan, combination chemotherapy, colorectal cancer
S-1, an oral fluoropyrimidine derivative, has been developed in combination with two biomodulators, 5-chloro-2,4dihaydroxy pyrimidine and potassium oxonate, to improve the therapeutic index of tegafur by maintaining high concentrations of 5-FU in plasma and tumors with less gastrointestinal toxicity (3). In Phase II studies, S-1 monotherapy for metastatic colorectal cancer has been demonstrated to be safe and shows a response rate ranging from 19 to $39.5 \%$ as a first-line treatment and of $14.3 \%$ as a second- or third-line treatment (4-7).

CPT-11, also known as irinotecan, is a DNA topoisomerase I inhibitor (8). Two randomized Phase III studies demonstrated that CPT-11 therapy combined with 5-FU plus leucovorin as a first-line treatment for advanced colorectal cancer was highly effective, providing a response rate of $35-39 \%$, a progression-free survival of 6.7-7.0 months and an overall survival of 14.8-17.4 months $(9,10)$. Following these reports, this combination therapy was recognized as the standard chemotherapy for colorectal cancer. Nonetheless, several studies have attempted to use oral fluoropyrimidine derivatives such as capecitabine and $\mathrm{S}-1$, instead of $5-\mathrm{FU}$ plus leucovorin, in combination with CPT-11 (11-14). These studies have also shown favorable results in terms of their efficacy and safety. However, no standard treatment schedule, including dose setting and cycle duration, has been established.

We conducted a Phase I/II study of combination therapy with CPT-11 and S-1 as a first-line treatment for metastatic colorectal cancer to determine the recommended dose (RD) and to evaluate the efficacy and safety of treatment at this dose.

\section{Patients and methods}

Patient selection. Before entry, patients underwent a physical examination, a chest X-ray and computed tomographic scans of the abdomen and chest. A complete blood cell count, a liver and renal function test and urinalysis were performed 7 days prior to admittance. The main eligibility criteria included a histologically confirmed diagnosis of colorectal cancer with metastatic disease, measurable disease, age $\geq 20$ years, life expectancy $\geq 12$ weeks, an Eastern Cooperative Oncology Group performance status $\leq 2$, a leukocyte count of $4,000-12,000 / \mathrm{mm}^{3}$, a platelet count $\geq 100,000 / \mathrm{mm}^{3}$, 
hemoglobin $\geq 9.5 \mathrm{~g} / \mathrm{dl}$, serum aspartate aminotransferase $\leq 100 \mathrm{IU} / 1$, alanine aminotransferase $\leq 100 \mathrm{IU} / 1$, bilirubin $\leq 2.0 \mathrm{mg} / \mathrm{dl}$, and serum creatinine $\leq 1.5 \mathrm{mg} / \mathrm{dl}$. Patients who had undergone previous chemotherapy were not included, except for those who had undergone adjuvant chemotherapy $\geq 6$ months before. Patients with the following conditions were not eligible: unresolved bowel obstruction or diarrhea, central nervous system metastasis, clinically significant heart disease, active carcinoma with the primary site in organs other than the colon and rectum, active infection, a past history of severe drug allergy, fresh gastrointestinal bleeding and pleural and/or peritoneal effusion needing treatment. The study was approved by the ethics committee for clinical research of Saga University Hospital. Patients were informed of the investigational nature of the study and provided their written informed consent before registration.

Study design and treatment. The study was designed as a Phase I study to determine the maximum-tolerated dose (MTD) and RD of S-1 (Taiho Pharmaceutical Co. Ltd., Tokyo, Japan) and of CPT-11 (Irinotecan; Yakult Pharmaceutical Co. Ltd., Tokyo, Japan), and as a Phase II study evaluating the efficacy and safety of treatment using these RDs. The 28-day treatment cycle consisted of CPT-11 in $500 \mathrm{ml}$ of saline administered intravenously over a 90-min period on days 1 and 15, and of S-1 administered orally in two divided doses for 21 consecutive days, from day 1 to 21 . Treatment was repeated unless disease progression or severe toxicity was observed.

The dose of S-1 was fixed at $80 \mathrm{mg} / \mathrm{m}^{2} /$ day according to the Japanese RD. Based on a previous study, three doses of S-1 were used according to body surface area (BSA) as follows: BSA $<1.25 \mathrm{~m}^{2}, 80 \mathrm{mg} /$ day; BSA $1.25-1.5 \mathrm{~m}^{2}, 100 \mathrm{mg} /$ day; BSA $>1.5 \mathrm{~m}^{2}, 120 \mathrm{mg} /$ day (5). CPT-11 was administered at a starting dose of $60 \mathrm{mg} / \mathrm{m}^{2}$ (level 1) then increased in $20 \mathrm{mg} / \mathrm{m}^{2}$ increments to $120 \mathrm{mg} / \mathrm{m}^{2}$ (level 4) unless the MTD was achieved. The MTD was defined as the dose level associated with dose-limiting toxicity (DLT) in at least two of three and two of six patients ( $>33 \%$ of patients). The DLT was defined as the occurrence of one or more of the following toxicities during the first course: febrile grade 3 or 4 hematological toxicity, grade 4 neutropenia, grade 4 thrombocytopenia, grade 3 or 4 non-hematological toxicity except for nausea and vomiting, or a >1-week delay in treatment as a result of drugrelated toxicity. The number of patients at each dose level was based on DLTs experienced during the first course. Proceeding to the next dose level was allowed if none of the three patients at a given dose developed DLT. If one of three patients at a given dose developed DLT, three or more patients were entered at the same dose. Proceeding to the next dose level was allowed if none of the additional patients developed a DLT, but not if one or more did. Before proceeding to the next dose level, all patients had received at least one course of treatment. No intrapatient dose escalation was allowed.

The following course was started only for patients who met the criteria of a leukocyte count of $3,000-12,000 / \mathrm{mm}^{3}$, a platelet count $\geq 100,000 / \mathrm{mm}^{3}$, body temperature $<38^{\circ} \mathrm{C}$, and other toxicities of grade 2 or less except for nausea, alopecia and skin pigmentation. If the patient condition was not resolved by day 42 of the cycle, treatment was discontinued. If the patients exhibited grade 4 neutropenia, grade 4 throm-
Table I. Patient characteristics.

\begin{tabular}{|c|c|c|c|}
\hline \multirow[b]{2}{*}{ Level } & \multicolumn{2}{|c|}{ Phase I } & \multirow[t]{2}{*}{ Phase $\mathrm{II}^{\mathrm{a}}$} \\
\hline & 1 & 2 & \\
\hline CPT-11 & 60 & 80 & 60 \\
\hline No. of patients & 6 & 3 & 33 \\
\hline \multicolumn{4}{|l|}{ Age (years) } \\
\hline Mean & 60 & 65 & 66 \\
\hline Range & $43-73$ & $53-73$ & $41-85$ \\
\hline \multicolumn{4}{|l|}{ Gender } \\
\hline Male & 4 & 3 & 18 \\
\hline Female & 2 & 0 & 15 \\
\hline \multicolumn{4}{|l|}{ Perfomance status (ECOG) } \\
\hline PSO & 4 & 2 & 17 \\
\hline PS1 & 1 & 1 & 10 \\
\hline PS2 & 1 & 0 & 6 \\
\hline \multicolumn{4}{|l|}{ Primary lesions } \\
\hline Colon & 3 & 0 & 20 \\
\hline Rectum & 3 & 3 & 13 \\
\hline \multicolumn{4}{|l|}{ Histological type } \\
\hline Well & 1 & 1 & 12 \\
\hline Moderate & 3 & 2 & 13 \\
\hline Poor & 1 & 0 & 5 \\
\hline Other (muc./sig.) & 1 & 0 & 3 \\
\hline \multicolumn{4}{|l|}{ No. of organs involved } \\
\hline 1 & 2 & 1 & 12 \\
\hline 2 & 2 & 2 & 13 \\
\hline$\geq 3$ & 2 & 0 & 8 \\
\hline \multicolumn{4}{|l|}{ Prior therapy } \\
\hline Surgery for primary lesions & 3 & 3 & 24 \\
\hline Surgery for metastatic lesions & 0 & 0 & 5 \\
\hline Adjuvant chemotherapy & 2 & 1 & 11 \\
\hline
\end{tabular}

ancludes six patients at level 1 of the Phase I portion.

bocytopenia, grade 3 or 4 diarrhea or treatment delay due to neutropenia or diarrhea, the dose of CPT-11 was reduced by $10 \mathrm{mg} / \mathrm{m}^{2}$ in the subsequent course. Under the same conditions, the dose of S-1 was reduced in the subsequent course as follows: 120,100 , and $80 \mathrm{mg}$ of $\mathrm{S}-1$ daily were respectively reduced to 100,80 , and $50 \mathrm{mg}$ daily. Once reduced, the doses of CPT-11 and S- 1 were not increased. If the patients exhibited a reaction requiring a second dose reduction, treatment was discontinued.

Supportive treatments were administered as required. Patients with diarrhea were treated with loperamide hydrochloride. The prophylactic administration of antiemetic medication (5-HT3 antagonist and corticosteroid) and antigastrointestinal mucositis ( $\mathrm{H} 2$ receptor blocker) at standard doses was routinely performed when CPT-11 was administered. The use of colony-stimulating factors was allowed if medically justified. 
Table II. Incidence of toxicity.

\begin{tabular}{|c|c|c|c|c|c|c|}
\hline & \multicolumn{4}{|c|}{ Phase I (first course) } & \multirow{2}{*}{\multicolumn{2}{|c|}{$\frac{\text { Phase } \text { II }^{\mathrm{a}}(\text { all courses })}{(\mathrm{n}=33)}$}} \\
\hline & \multicolumn{2}{|c|}{ Level $1(n=6)$} & \multicolumn{2}{|c|}{ Level $2(n=3)$} & & \\
\hline & $\begin{array}{l}\text { Any grade } \\
\qquad \%)\end{array}$ & $\begin{array}{c}\text { Grades 3-4 } \\
(\%)\end{array}$ & $\begin{array}{l}\text { Any grade) } \\
(\%)\end{array}$ & $\begin{array}{c}\text { Grades } 3-4 \\
(\%)\end{array}$ & $\begin{array}{l}\text { Any grade } \\
(\%)\end{array}$ & $\begin{array}{c}\text { Grades 3-4 } \\
(\%)\end{array}$ \\
\hline Any toxicity & $5(83)$ & $1(17)$ & $3(100)$ & $2(67)$ & $31(94)$ & $6(18)$ \\
\hline \multicolumn{7}{|l|}{ Hematological toxicity } \\
\hline Anemia & $4(67)$ & $0 \quad(0)$ & 1 (33) & $0 \quad(0)$ & $29(88)$ & 1 (3) \\
\hline Leucopenia & $3(50)$ & $0 \quad(0)$ & $2(67)$ & $1(33)$ & $16(48)$ & 1 (3) \\
\hline Neutropenia & $3(50)$ & $0 \quad(0)$ & $2(67)$ & $1(33)$ & $17(52)$ & $1 \quad(3)$ \\
\hline Thrombocytopenia & $2(33)$ & $0 \quad(0)$ & 1 (33) & $1(33)$ & $10(30)$ & $0 \quad(0)$ \\
\hline \multicolumn{7}{|l|}{ Non-hematotogical toxicity } \\
\hline Diarrhea & $3(50)$ & $1(17)$ & $2(67)$ & $1(33)$ & $21(64)$ & $2(6)$ \\
\hline Colitis & $0(0)$ & $0 \quad(0)$ & $0 \quad(0)$ & $0 \quad(0)$ & $1 \quad(3)$ & $1 \quad(3)$ \\
\hline Anorexia & $5(83)$ & $0 \quad(0)$ & $2(67)$ & $0 \quad(0)$ & $31(94)$ & $1 \quad(3)$ \\
\hline Nausea & $4(67)$ & $0 \quad(0)$ & $2(67)$ & $0 \quad(0)$ & $24(72)$ & $0 \quad(0)$ \\
\hline Vomiting & $2(33)$ & $0 \quad(0)$ & $1 \quad(33)$ & $0 \quad(0)$ & $11(33)$ & $0 \quad(0)$ \\
\hline Stomatitis & $3(50)$ & $0 \quad(0)$ & 1 (33) & $0 \quad(0)$ & $21(64)$ & $0 \quad(0)$ \\
\hline Fatigue & $5(83)$ & $0 \quad(0)$ & $2(67)$ & $0 \quad(0)$ & $31(94)$ & $0 \quad(0)$ \\
\hline Changes in liver function & $1(17)$ & $0 \quad(0)$ & $0 \quad(0)$ & $0 \quad(0)$ & $13(39)$ & $0 \quad(0)$ \\
\hline Changes in renal function & $1(17)$ & $0 \quad(0)$ & $0 \quad(0)$ & $0 \quad(0)$ & $4(12)$ & $0 \quad(0)$ \\
\hline Skin pigmentation & $4(67)$ & $0 \quad(0)$ & $1 \quad(33)$ & $0 \quad(0)$ & $22(67)$ & $0 \quad(0)$ \\
\hline Hand-foot syndrome & $1(17)$ & $0 \quad(0)$ & $0 \quad(0)$ & $0 \quad(0)$ & $6(18)$ & $0 \quad(0)$ \\
\hline
\end{tabular}

ancluding six patients at level 1 of the Phase I portion.

Evaluation. A complete blood cell count, a liver and renal function test and urinalysis were conducted at least once a week during the first and second courses, and every other week afterwards. Toxicity was assessed according to the National Cancer Institute Common Toxicity Criteria (NCICTC) version 2.0. Toxicity profiles and dose intensity (DI) were determined at the end of the treatment course. Relative DI was calculated using the formula (\%): $100 \mathrm{x}$ delivered DI $\left(\mathrm{mg} / \mathrm{m}^{2} / \mathrm{wk}\right) /$ projected DI $\left(\mathrm{mg} / \mathrm{m}^{2} / \mathrm{wk}\right)$. Patients were examined with at least 6-week intervals to evaluate objective responses. Responses were evaluated according to the RECIST criteria (15). Complete and partial responses required subsequent confirmation of response after an interval of at least 4 weeks. Progression-free and overall survival were calculated from the day treatment started to the day of evaluation on which disease progression was confirmed and the day the patient succumbed to the disease, respectively.

Statistics. We calculated the required sample size for the Phase II study on the basis of a target activity level of $40 \%$ and a minimum activity level of $20 \%$, with $\alpha$ and $\beta$ errors of 0.2 . The required number of patients was estimated to be 24 . Progression-free and overall survival curves were estimated using the Kaplan-Meier method and tested by the log-rank test. Significant difference was defined as $\mathrm{P}<0.05$.

\section{Results}

Between April 2003 and March 2006, 36 patients were enrolled in the present study. The first nine were entered into the Phase I portion and the remaining 27 into the Phase II portion. The MTD and RD were determined by evaluating the nine patients in the Phase I study. Efficacy and safety were analyzed in 33 patients receiving the RD as an initial dose, including six patients assigned to level 1 in the Phase I study. At the last evaluation, treatment based on the protocol was discontinued in all eight surviving patients. Patients were eligible for a toxicity evaluation during any course and a response evaluation. The characteristics of the 36 patients are summarized in Table I.

MTD and RD. At level 1 in the Phase I study, one of three patients developed grade 3 diarrhea during the first course, but the other two patients exhibited no DLT (Table II). An additional three patients at level 1 showed no DLT. We enrolled three patients into the Phase I study at level 2. One patient developed grade 3 diarrhea during the first course. Another patient presented grade 3 leucopenia, neutropenia and thrombocytopenia, which were not DLTs in and of themselves. However, leukocyte and platelet counts had not recovered to starting criteria levels by the following course on day 36. Therefore, these toxicities were categorized as 
Table III. Efficacy.

\begin{tabular}{lc}
\hline Response (No. of patients ${ }^{\mathrm{a}}$ ) & \\
Complete response & 4 \\
Partial response & 15 \\
Stable disease & 8 \\
Progressive disease & 5 \\
Not evaluated & 1 \\
Response rate (\%) & \\
Rate & 58 \\
95\% CI & $41-75$ \\
Disease control rate (\%) & \\
Rate & 82 \\
$95 \%$ CI & $67-96$ \\
\hline
\end{tabular}

${ }^{a}$ Total number of patients, 33 .

DLTs, since the second course of treatment for this patient was delayed by more than a week. The third level 2 patient exhibited no DLT. According to protocol, no patient was entered into the group at dose level 3, and dose level 2 was declared to be the MTD.

At level 2, treatment for patients presenting DLT was discontinued due to toxicity after the second course. The patient with grade 3 diarrhea continued to suffer from grade 3 diarrhea during the second course, despite dose reduction. The patient with grade 3 hematological toxicity continued to exhibit similar toxicity, which did not recover to the starting criteria levels required for the following course on day 43. Regarding treatment continuation, dose level 2 was considered to be unsuitable as the RD. Therefore, further observation of safety and efficacy was performed to confirm whether to proceed to a Phase II study using dose level 1. One of the six patients at level 1 again developed grade 3 diarrhea during the second course despite dose reduction, but none of the other five patients showed grade 3 or 4 toxicity during the first six treatment courses. Regarding best response to treatment, one patient had a complete response, three a partial response, one stable disease and one progressive disease. Dose level 1 was finally determined to be the RD for the Phase II study.

Safety. During the treatment courses, no treatment-related deaths occurred. The numbers of patients showing each toxic reaction are summarized in Table II according to the worst grade per patient. The most common hematological toxicity was anemia, and the most common non-hematological toxicities were anorexia and fatigue. Although $94 \%$ of the patients $(31 / 33)$ showed some toxic reactions, most of these were mild. Grade 3 or 4 toxicity occurred in $18 \%$ of the patients $(6 / 33)$. Observed grade 3 toxic reactions were anemia (3\%), leucopenia (3\%), neutropenia (3\%), diarrhea $(6 \%)$, colitis $(3 \%)$ and anorexia (3\%). There were no grade 4 toxic reactions.

A total of 274 treatment courses were performed in the study. The median number of courses was 8 (range 1-16). The mean DI of CPT-11 was $29 \mathrm{mg} / \mathrm{m}^{2} / \mathrm{wk}$. The mean DI of S-1 was $407 \mathrm{mg} / \mathrm{m}^{2} / \mathrm{wk}$. The mean relative DI of CPT-11 and S-1

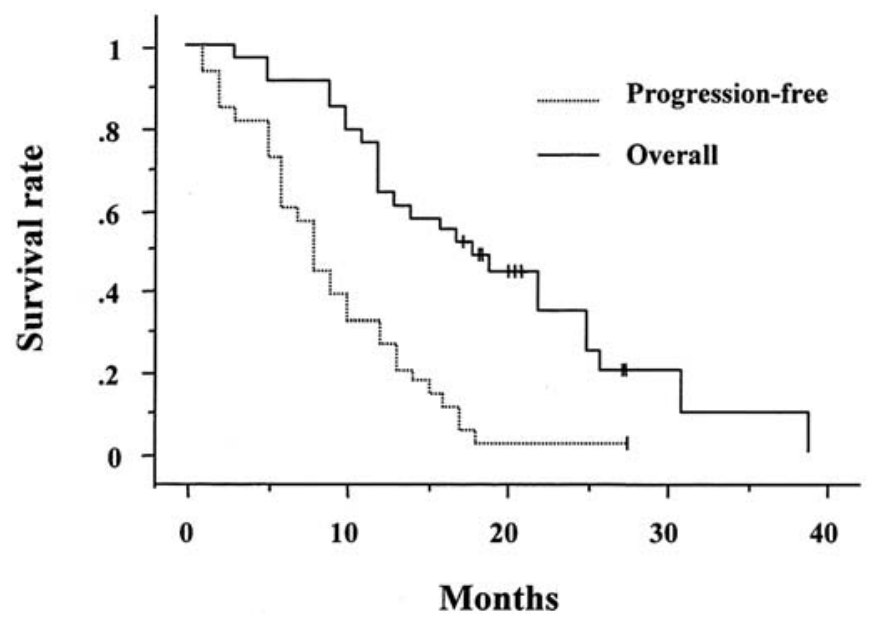

Figure 1. Progression-free and overall survival. Median progression survival was 8.4 months and median overall survival was 18.7 months.

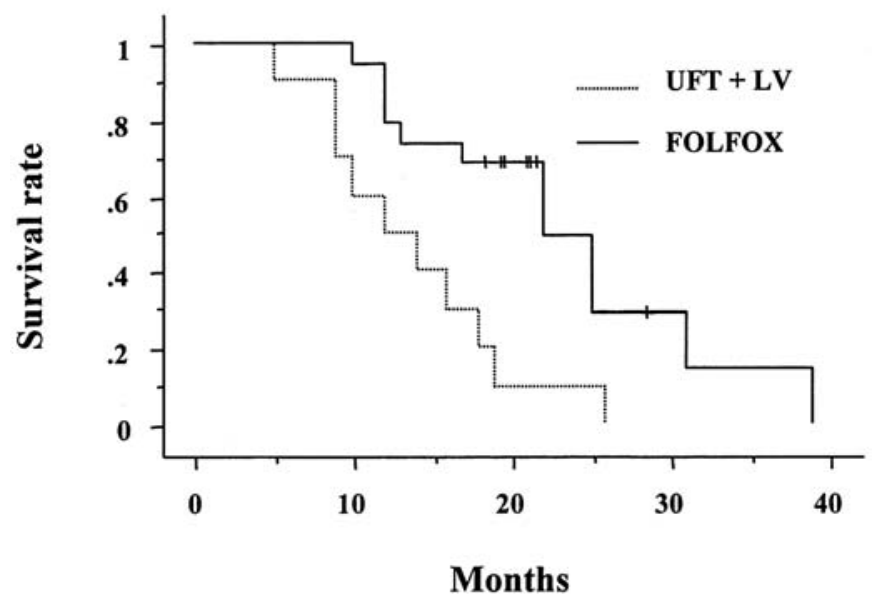

Figure 2. Overall survival with second-line treatment. The survival (median $>22.2$ months) of patients receiving FOLFOX as second-line treatment was significantly longer than that of those receiving UFT/LV (median 13.0 months) $(\mathrm{P}=0.0027)$.

was as high as 98 and $97 \%$, respectively. Due to toxicity, a delay in treatment occurred in 15 patients. Dose reduction was performed in two patients. A toxic reaction as the reason for dose reduction was diarrhea. The reasons for treatment discontinuation were tumor progression in 26 patients, toxicity in five, and patient refusal in two. Toxic reactions as the reason for treatment discontinuation were anemia, febrile neutropenia, diarrhea and colitis. Two patients had grade 3 diarrhea requiring a second dose reduction. In the other three patients, treatment was discontinued because of prolonged toxic effects that were still not resolved over 42 days after the toxicityinducing course was initiated.

Efficacy. In terms of best response to treatment, four patients had a complete response, 15 a partial response, eight stable disease and five progressive disease (Table III). One patient was not evaluated due to refusal of further treatment or examination. The response rate was 58\% [19/33, 95\% confidence interval (CI) 41-75\%] and the disease control rate $82 \%$ (27/33, $95 \%$ CI $67-96 \%)$. In 19 responders, the median time to 
response and duration of response were 1.5 months (range 1.5-4.5) and 8.0 months (range 3.0 to $>27.0$ ), respectively. The median time of progression-free survival was 8.4 months (range 1.5 to $>28.5$ ) and of overall survival 18.7 months (range 3.2-39.0) (Fig. 1).

Twenty-nine of 33 patients in the Phase II portion received second-line treatment with either oxaliplatin and 5-FU plus leucovorin (FOLFOX) or tegafur/uracil and oral leucovorin (UFT/LV). In the subgroup analysis of second-line treatment, the median overall survival of 19 patients receiving FOLFOX was $>22.2$ months, which was significantly longer than that of 10 patients receiving UFT/LV (13.0 months, $\mathrm{p}=0.0027$ ) (Fig. 2).

\section{Discussion}

There have been several reports on Phase I studies of combination therapy with CPT-11 and S-1 that aimed to determine the RD for advanced gastric or colorectal cancer (16-20). Although the same dose $\left(80 \mathrm{mg} / \mathrm{m}^{2} /\right.$ day $)$ of $\mathrm{S}-1$ was used here as in the other studies, the RDs for CPT-11 differ between the reports. The RD of CPT-11 appears to be determined by treatment schedule, which can be classified into three groups according to the time of CPT-11 administration and the duration of S-1 administration in a cycle. In the first group, the RD of CPT-11 was $150 \mathrm{mg} / \mathrm{m}^{2}$ in a 3-week treatment cycle consisting of CPT-11 administered on day 1 and S-1 administered for 14 consecutive days, from day 1 to 14 (16). In the second group, the RD of CPT-11 was determined to be $80 \mathrm{mg} / \mathrm{m}^{2}$ in a 5 -week treatment cycle consisting of CPT-11 administered on days 1 and 15 and S-1 administered for 21 consecutive days, from day 1 to $21(17,18)$. In the third group, the RD of CPT-11 was also determined to be $80 \mathrm{mg} / \mathrm{m}^{2}$ in a 3- or 4-week treatment cycle consisting of CPT-11 administered on days 1 and 8 and S-1 administered for 14 consecutive days, from day 1 to $14(19,20)$. In the present study, however, the RD of CPT-11 was determined to be $60 \mathrm{mg} / \mathrm{m}^{2}$. Our treatment schedule was similar to that of the second group except for the length of the cycle (4 vs. 5 weeks). The protocols of the two studies in the second group as well as ours included the delay of treatment as a DLT. Adding the permitted delay, the maximum length of the cycle in our study was 5 weeks, while that of the cycle in the second group was 6-7 weeks. This may explain why, in our study, the MTD was achieved at $80 \mathrm{mg} / \mathrm{m}^{2}$ of CPT- 11 , not at $100 \mathrm{mg} / \mathrm{m}^{2}$ as reported in the second group. DLT in one patient treated with our protocol at $80 \mathrm{mg} / \mathrm{m}^{2}$ of CPT-11 was prolonged hematological toxicity. However, the patient recovered to starting criteria levels on day 43 of the first course.

In the Phase II portion of the present study, the high feasibility of our treatment was demonstrated by the high relative DI (CPT-11 98\% and S-1 97\%). There are two other Phase II studies of this combination therapy, enrolling $>30$ patients. Inokuchi et al (19) showed a high relative DI (CPT-11 94\% and S-1 98\%) for gastric cancer, while a lower relative DI (CPT-11 87\% and S-1 82\%) was reported by Goto et al (13) in a study on colorectal cancer. Compared to the latter (CPT-11 $50 \mathrm{mg} / \mathrm{m}^{2} / \mathrm{wk}$ and S-1 $373 \mathrm{mg} / \mathrm{m}^{2} / \mathrm{wk}$ ), the former used the lower projected DI of the two agents (CPT-11 $40 \mathrm{mg} / \mathrm{m}^{2} / \mathrm{wk}$ and S-1 $280 \mathrm{mg} / \mathrm{m}^{2} / \mathrm{wk}$ ). By our RD, the pro- jected DI of CPT-11 $\left(30 \mathrm{mg} / \mathrm{m}^{2} / \mathrm{wk}\right)$ was lower than that of the two previous reports, but that of S-1 $\left(420 \mathrm{mg} / \mathrm{m}^{2} / \mathrm{wk}\right)$ was higher. Therefore, the relative DI may have decreased when we selected a higher dose of CPT-11 as RD in our treatment schedule.

The efficacy of our combination therapy was comparable to that of combination therapy with CPT-11 and S-1 following a different treatment schedule, and to that of combination therapy with CPT-11 and 5-FU plus leucovorin. A previous Phase II report on CPT-11 and S-1 combination therapy showed a response rate of $62.5 \%$ (cf. $58 \%$ in the present study), and a median progression-free survival of 8.0 months (cf. 8.4 months in the present study) (13). Phase III studies of combination therapy with CPT-11 and 5-FU plus leucovorin demonstrated response rates and progression-free survival times of $31-62 \%$ and 6.7-8.7 months, respectively $(9,10)$.

Capecitabine, another oral fluoropyrimidine derivative, is well known for its use in combination with CPT-11 for colorectal cancer treatment. The efficacy of this combination therapy was demonstrated by $44-50 \%$ response rates and 7.6-8.3 months of progression-free survival, but the incidence of grade 3 or 4 diarrhea was reported to be as high as $20-27 \%$ $(11,12)$. In contrast, two Phase II studies of CPT-11 and S-1 combination therapy, including ours, have shown a rate of grade 3 or 4 diarrhea of 6-7.5\% (13). As for hand-foot syndrome, the incidence and severity in the studies on CPT-11 and S-1 is clearly low. Therefore, a combination of CPT-11 and $\mathrm{S}-1$ is safer than one of CPT-11 and capecitabine. Toxicity profiles between the two CPT-11 and S-1 combination therapy studies were very similar, but severe toxicities were less frequently observed in the present study. Grade 3 or 4 neutropenia and grade 3 anorexia occurred in $>10 \%$ of the patients during the first six treatment courses in the prior study. The incidence of grade 3 or 4 toxic reactions, however, was $<5 \%$ in all patients for any toxicity except diarrhea (6\%) during all treatment courses of our study. Consequently, our regimen appears to be safer than that of the prior study.

The present study is the first Phase II study of colorectal cancer to report the median overall survival (18.7 months) of patients receiving CPT-11 and S-1 combination therapy as a first-line treatment for metastatic colorectal cancer. In the subgroup analysis, the median overall survival of patients receiving FOLFOX as a second-line treatment was $>22.2$ months. This median overall survival was comparable to that of FOLFIRI followed by FOLFOX6 (21.5 months) and the reverse sequence (20.6 months) (21). When we started the present study, oxaliplatin was not available in Japan. Until April 2005, when oxaliplatin was formally introduced, all patients receiving second-line treatment were treated with UFT/LV (22). The median overall survival of these patients was 13.0 months, which is significantly shorter than that of patients receiving FOLFOX. This finding supports the hypothesis by Grothey et al (23) that the availability of all three active drugs (5-FU-leucovorin, CPT-11 and oxaliplatin) improves survival in patients with advanced colorectal cancer.

In conclusion, we have demonstrated that a combination therapy using CPT-11 and S-1 according to our treatment schedule is effective, safe, and highly feasible for metastatic colorectal cancer patients. These data suggest that it is worth assessing this combination therapy in a Phase III study. 


\section{References}

1. Jemal A, Shiegel R, Ward E, Murray T, Xu J and Thum MJ: Cancer statistics. CA Cancer J Clin 57: 43-66, 2007.

2. Goldberg RM, Sargent DJ, MortonRF, Fuchs CS, Ramanathan RK, Williamson SK, Findlay BP, Pitot HC and Albert SR: A randomized controlled trial of fluorouracil plus leucovorin, irinotecan, and oxaliplatin combinations in patients with previously untreated metastatic colorectal cancer. J Clin Oncol 22: 23-30, 2004.

3. Shirasaka T, Shimamoto Y, Ohshimo H, Yamaguchi M, Kato T, Yonekura K and Fukushima M: Development of a novel form of an oral 5-fluorouracil derivative (S-1) directed to the potentiation of the tumor selective cytotoxicity of 5-fluorouracil by two biochemical modulators. Anticancer Drugs 7: 548-557, 1996.

4. Jeung HC, Rha SY, Cho BC, Yoo NC, Roh JK, Roh WJ, Chung HC and Ahn JB: A phase II trial of S-1 monotherapy in metastatic colorectal cancer after failure of irinotecan- and oxaliplatin-containing regimens. Br J Cancer 95: 1637-1641, 2006.

5. Ohtsu A, Baba H, Sakata Y, MitachiY, Horikoshi N, Sugimachi K and Taguchi T: Phase II study of S-1, a novel oral fluoropyrimidine derivative, in patients with metastatic colorectal carcinoma. Br J Cancer 83: 141-145, 2000.

6. Shirao K, Ohtsu A, Takada H, Mitachi Y, Hirakawa K, Horikoshi N, Okamura T, Hirata K, Saitoh S, Isomoto H and Sato A: Phase II study of oral S-1 for treatment of metastatic colorectal carcinoma. Cancer 100: 2355-2361, 2004

7. Van den Brande J, Schöffski P, Schellens JHM, Roth AD, Duffaud F, Wegang-Köhler, Reinke F, Wanders J, De Boer RF, Vermorken JB and Fumoleau P: EORTC Early Clinical Studies Group early phase II trial of S-1 in patients with advanced or metastatic colorectal cancer. Br J Cancer 88: 648-653, 2003.

8. Kawano Y, Aonuma M, Hirota Y, Kuga H and Sato K: Intracellular roles of $\mathrm{SN}-38$, a metabolite of the comptothecin derivative CPT-11, in the antitumor effect of CPT-11. Cancer Res 49: 4187-4191, 1991.

9. Douillard JY, Cunningham D, Roth AD, Navarro M, James RD, Karasek P, Jandik P, Iveson T, Cramichael J, Alakl M, Gruia G, Awad L and Rougier P: Irinotecan combined with fluorouracil compared with fluorouracil alone as first-line treatment for metastatic colorectal cancer: a multicentre randomized trial. Lancet 355: 1041-1047, 2000

10. Saltz LB, Cox JV, Blanke C, Rosen LS, Fehrenbacher L, Moore MJ, Maroun JA, Ackland SP, Locker PK, Pirotta NP, Elfring GL and Miller LL: Irinotecan plus fluorouracil and leucovorin for metastatic colorectal cancer. N Engl J Med 343: 905-914, 2000

11. Bajetta E, Di Bartolomeo M, Mariani L, Cassata A, Artale S, Frustaci S, Pinotti G, Bonetti A, Carreca I, Biasco G, Bonaglia L, Marini G, Iannelli A, Cortinovis D, Ferrario E, Beretta E, Lambiase A and Bussoni R: Randomized multicenter phase II trial of two different schedules of irinotecan combined with capecitabine as first line treatment in metastatic colorectal carcinoma. Cancer 100: 279-287, 2004.
12. Patt YZ, Lee F-C, Liebmann JE, Diamandidis D, Eckhardt SG, Javle M, Justice GR, Keiser W, Salvatore JR, Bexon A and Lin E: Capecitabine plus 3-weekly irinotecan (XELIRI regimen) as first-line chemotherapy for metastatic colorectal cancer. Phase II trial results. Am J Clin Oncol 30: 350-357, 2007.

13. Goto A, Yamada H, Yasui H, Kato K, Hamaguchi T, Muro K, Shimada Y and Sirao K: Phase II study of combination therapy with S-1 and irinotecan in patients with advanced colorectal cancer. Ann Oncol 17: 968-973, 2006.

14. Yosahimatsu K, Yokomizo H, Fujimoto T, Umehara A, Otani T, Matsumoto A, Osawa G and Ogawa K: Pilot study of simplified low-dose S-1 plus CPT-11 as first-line chemotherapy for patients with advanced colorectal cancer. Anticancer Res 27: 1657-1662, 2007.

15. Therasse P, Arbuck SG, Eisenhauer EA, Wanders J, Kaplan RS, Rubinstein L, Verweij J, van Glabbeke M, van Oosterom AT, Christian MC and Gwyther SG: New guidelines to evaluate the response to treatment in solid tumors. J Natl Cancer Inst 92: 205-216, 2000

16. Yamada Y, Yasui H, Goto A, Arai T, Ura T, Hamaguchi T, Muro K, Shimada Y and Shirao K: Phase I study of irinotecan and S-1 combination therapy in patients with metastatic gastric cancer. Int J Clin Oncol 8: 374-380, 2003.

17. Takiuchi H, Narahara H, Tsujinaka T, Gotoh M, Kawabe S, Katsu K, Ishii $\mathrm{H}$, Tatsuta M, Fujitani K, Furukawa $\mathrm{H}$ and Taguchi T: Phase I study of S-1 combined with irinotecan (CPT-11) in patients with advanced gastric cancer (OGSG 0002). Jpn J Clin Oncol 35: 520-525, 2005.

18. Tsunoda A, Yasuda N, Nakao K, Narita K, Yamazaki K, Watanabe M, Suzuki N and Kusano M: Phase I study S-1 combined with irinotecan (CPT-11) in patients with advanced colorectal cancer. Oncology 72: 58-63, 2007.

19. Inokuchi M, Yamashita T, Yamada H, Kojima K, Ichikawa W, Nihei Z, Kawano T and Sugihara K: Phase I/II study of S-1 combined with irinotecan for metastatic advanced gastric cancer. Br J Cancer 94: 1130-1135, 2006.

20. Katsube T, Ogawa K, Ichikawa W, Fujii M, Tokunaga A, Takagi Y, Kochi M, Hayashi K, Kubota T, Aiba K, Arai K, Terashima $\mathrm{M}$ and Kitajima M: Phase I/II study of irinotecan (CPT-11) and S-1 in the treatment of advanced gastric cancer. Anticancer Drugs 18: 605-610, 2007.

21. Tournigand C, André T, Achille E, Lledo G, Flesh M, MeryMiugnard D, Quinaux E, Couteau C, Buyse M, Ganem G, Landi B, Colin P, Louvet C and de Gramont A: FOLFIRI followed by FOLFOX6 or the reversed sequence in advanced colorectal cancer: a randomized GERCOR study. J Clin Oncol 22: 229-237, 2004.

22. Carmichael J, Popiela T, Radstone AD, Falk S, Borner M, Oza A, Skovgaard T, Munier S and Martin C: Randomized comparative study of tegafur/uracil and oral leucovorin versus parenteral fluorouracil and leucovorin in patients with previously untreated metastatic colorectal cancer. J Clin Oncol 20: 3617-3627, 2002.

23. Grothey A, Sargent D, Goldberg RM and Schmoll H-J: Surviva of patients with advanced colorectal cancer improves with availability of fluorouracil-lucovorin, irinotecan, and oxaliplatin in the course of treatment. J Clin Oncol 22: 1209-1214, 2004. 